\title{
Entrevista a Alicia Girón
}

\author{
4 de febrero de 2021
}

Revista Derechos en Acción ISSN 2525-1678/ e-ISSN 2525-1686

Año 6/No 18, Verano 2020-2021 (21 diciembre a 20 marzo), 892-897

DOl: https://doi.org/10.24215/25251678e505

Alicia Girón es una economista mexicana, doctora en Estudios Latinoamericanos por la Universidad Nacional Autónoma de México. Sus principales líneas de investigación son economía financiera, particularmente relacionadas con los ciclos económicos, crisis financieras, deudas soberanas y sistemas financieros. Es integrante del Instituto

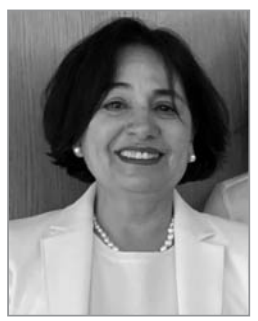
de Investigaciones Económicas (IIEc) de su alma mater, instituto que dirigió entre 1994 y 2002. Desde 2010 hasta 2018 fue editora de la revista Problemas del Desarrollo. Revista Latinoamericana de Economía. Es coordinadora del Programa Universitario de Estudios sobre Asia y África (PUEAA) desde 2017. Fue presidenta de la International Association for Feminist Economics (IAFFE) entre 2015 y 2016, e integrante del Alto Panel para el Empoderamiento Económico de las Mujeres de Naciones Unidas (2016-2017).

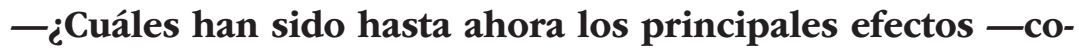
munes y diferenciados - de la pandemia y las medidas para contenerla sobre la situación económica y social de América Latina y el Caribe?

—En América Latina la caída del 9,1 \% del PIB durante 2020 ha impactado principalmente en el empleo, el incremento de la pobreza y un mayor endeudamiento público. COVID-19 llegó 
en un pésimo momento para la región dada las condiciones de vulnerabilidad financiera y económica al evidenciar las carencias en el acceso al agua, a la educación y a los sistemas de salud para enfrentar una pandemia.

Ante los efectos de la pandemia, el instrumento utilizado por los gobiernos ha sido la política fiscal. Ante más de tres décadas de haber utilizado las políticas de austeridad para estabilizar los indicadores macroeconómicos, hoy los países han incrementado el gasto social para lograr sanear las carencias. Si bien, todos los países de la región habían realizado una profunda reorganización del gasto público ante la evidencia de haber fallado en la canalización de su gasto social específicamente gasto en educación y gasto en salud. Incluso una muestra de orgullo de los gobiernos ha sido que hasta antes de la pandemia los países de América Latina habían reducido el déficit primario en América Latina, situándolo en el 0,6 \% del PIB en 2019, en comparación con el 1,1\% del PIB registrado en 2016. ${ }^{1}$ Por lo tanto, “(...) la política de gasto se ha centrado en la contención de su crecimiento, lo que ha incidido en una reducción del gasto primario para acomodar el peso cada vez mayor de los pagos de intereses". ${ }^{2}$

América Latina (como promedio de las cinco principales economías de la región) como parte de los países EMMIE, han respondido con medidas fiscales discrecionales destinando un 4,86\% del PIB para gastos adicionales e ingresos tributarios no percibidos. Por concepto de capitales, préstamos y garantías, la suma equivale al 3,04\% del PIB. Es importante resaltar la heterogeneidad de las cifras para las cinco principales economías de América Latina. Mientras países como Chile y Brasil han presentado respuestas fiscales que oscilan entre el 6,5\% y $8,3 \%$ del PIB, países como México no han superado el punto

\footnotetext{
1 CEPAL (2020). Estudio Económico de América Latina y el Caribe. Principales condicionantes de las políticas fiscal y monetaria en la era pospandemia de COVID-19. Santiago de Chile.

2 Ídem, p. 79.
} 
porcentual de su PIB en ninguno de los dos rubros estimados. Los casos de Argentina y Colombia - a septiembre de 2020 - se encontrarían en una situación media, al haber destinado entre $2,5 \%$ y $4 \%$ del PIB, como respuesta en términos fiscales para paliar la pandemia del COVID-19.

\section{- La historia de las últimas décadas de América Latina y el} Caribe están signadas por el peso de la deuda. ¿Qué explica esta gravitación sistemática? ¿Cuál ha sido el rol del FMI en la región? ¿Algún país intentó un camino alternativo?

-El sistema monetario de Bretton Woods creado en 1944 ha sido determinante en las políticas monetarias y fiscales de los países latinoamericanos. El crédito en la posguerra para los países latinoamericanos permitió proyectos de inversión que sirvieron en gran parte para el proceso industrial de países como Brasil y México. Los milagros económicos de estos países bajo el proceso de "industrialización por substitución de importaciones" fueron un ejemplo para otros países asiáticos.

El problema del endeudamiento es la carga tributaria del servicio de su deuda externa. A ello se suma que mucha deuda no ha sido canalizada para infraestructura sino para gasto corriente y ha incidido en corrupción de los gobiernos deudores.

Por lo tanto, el crédito en dólares a partir de la creación del Fondo Monetario Internacional y del Banco Mundial y posteriormente del Banco Interamericano de Desarrollo más la participación de la banca comercial estadounidense y europea definieron la moneda de intercambio internacional. El "dólar ha sido tan bueno como el oro". Hoy muchos países de la región han recibido con gran ánimo las inversiones directas y de capital, pero también están bajo el manto de los intereses de China por los recursos naturales. Desde la minería, hasta la soja, pasando por inversiones más específicas como puertos, aeropuertos y trenes.

La deuda externa ha sido el "talón de Aquiles" de América Latina desde que nace a la vida independiente. Se separó de la Corona española y de inmediato los intereses del Imperio 
Británico estaban en los recursos de la región. En mi opinión, podemos afirmar que existe una relación dialéctica del desarrollo del sistema capitalista entre los países europeos y los países latinoamericanos. El hecho de haber nacido sin una moneda nacional y sin la posibilidad que los países pudieran imponer una moneda dentro de su espacio regional propiciaron que el equivalente general soberano fuera la corona española y después la libra hasta llegar al dólar. El dólar ha marcado desde la Segunda Guerra Mundial hasta el día de hoy el equivalente con el que se realizan todas las operaciones de intercambio tanto a nivel internacional como a nivel regional. $\mathrm{Y}$, aunque algunos países han iniciado transacciones con yuanes, la moneda china difícilmente sustituirá al dólar.

- La mayoría de los países de la región están tomando más y más deuda para hacer frente a las erogaciones de emergencia para capear la pandemia. ¿Esta vía de financiamiento no generará mayor vulnerabilidad financiera y política a los países? ¿Qué mecanismos se podrían implementar para asegurar la sostenibilidad de las deudas públicas?

- La deuda pública se tiene que renegociar nuevamente y de momento plantear una moratoria. Una moratoria que le permita respirar a la región y canalizar ese excedente que se va a los fondos de pensiones y a los bedge funds especulativos. Quitas de capital, interés cero y reestructuración de los pagos a 100 años.

Las deudas son sostenibles cuando han sido canalizadas a sectores productivos de largo alcance como es infraestructura para crear nuevas industrias, servicios y crear empleo.

-Tomando en cuenta la actuación del FMI durante el 2020, ¿considera que el FMI ha aprendido las lecciones del pasado reciente en cuanto a que la austeridad no es una vía eficaz para el crecimiento, el desarrollo y la inclusión?, ¿o ya ve señales de austeridad en la intervención del FMI en la región y en el mundo? 
-El FMI se equivocó con las alternativas que se dieron a la crisis del 2008-2009 pero quiénes tienen la conciencia con remordimiento son los bancos centrales. Incluso cuando se presentó el resquebrajamiento de los bancos "muy grandes para quebrar, muy grandes para rescatar" los bancos centrales de inmediato salieron a salvar al sistema bancario y financiero. En la primera reunión del G20 allí se planteó la necesidad de la austeridad y reordenar las políticas públicas al pago de los acreedores. Incluso las tasas de interés al cero por ciento solo sirvieron para aumentar más la deuda de las corporaciones no financieras a nivel mundial y los países se endeudaron más. En mi opinión el endeudamiento cayó en una situación Ponzi, contratar deudas para pagar a los acreedores. Una situación que iba a explotar en cualquier momento. La COVID-19 solo vino a explotar el mal manejo de política monetaria, fiscal y financiero que implementaron los bancos centrales. Ellos son los culpables de la actual pandemia que está en marcha, la pandemia de la deuda.

En la última reunión del Foro Económico de Davos y en los discursos del FMI hay nuevos planteamientos al transmitir la necesidad del cambio en la forma en que se ha explotado la naturaleza. Hay una reflexión al mencionar la palabra "resetear" es decir volver a empezar. Esto implica que el endeudamiento contratado para ampliar el gasto público deberá llevarse a buen fin sin olvidar que estas instituciones responden a los inversionistas institucionales y los corporativos no financieros. Es el nuevo orden y la nueva división de los shareholders, o sea de los dueños de las acciones del capital empresarial internacional.

${ }_{-}$Es posible "arreglar" las instituciones de Bretton Woods para que sus recomendaciones de políticas estén en línea con las agendas para reducir las desigualdades, el cambio climático y la discriminación de género?

-Sí, es posible siempre y cuando tengan en mente que la otra mitad que carga al mundo son las mujeres. Políticas públicas con 
enfoque de género desde la educación, salud y trabajo digno para las mujeres mejorando el acceso a los servicios básicos terminarán paulatinamente con la pobreza y mejorarán la situación de las mujeres que son responsables de la reproducción social y de la vida en un espacio económico, político y social, la nación y el Estado. 